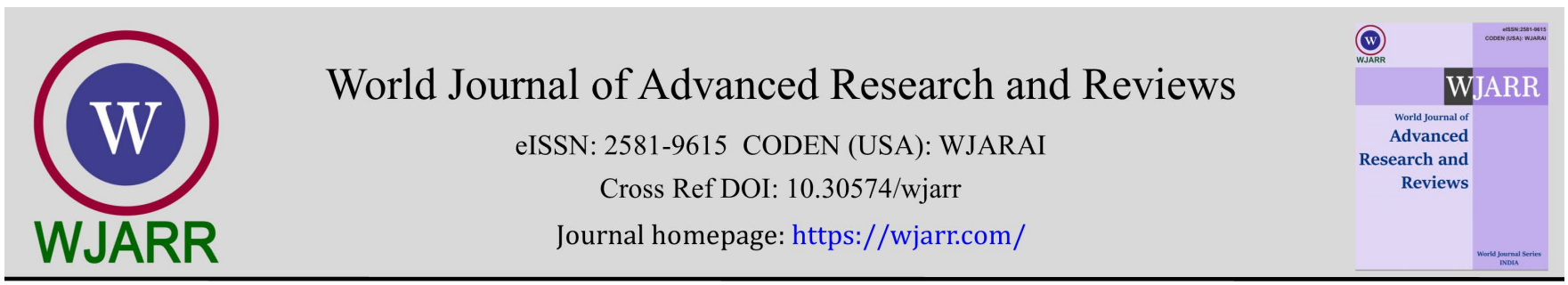

(REVIEW ARTICLE)

\title{
Sport Paradox: Sudden cardiac death
}

\author{
Muhammad Gazi Yasargil \\ Faculty of Medicine, Airlannga University, Indonesia.
}

World Journal of Advanced Research and Reviews, 2022, 13(01), 626-630

Publication history: Received on 20 December 2021; revised on 22 January 2022; accepted on 24 January 2022

Article DOI: https://doi.org/10.30574/wjarr.2022.13.1.0084

\begin{abstract}
One of the advantages of exercise/physical exercise is improvement of cardiovascular health, however if exercise is done incorrectly, it can lead to negative side-effects that are detrimental to the health of cardiovascular system. One of these side-effects is Sudden Cardiac Death (SDC) or Sprots-related Sudden Cardiac Death (SrSCD). The purpose of this literature review is to find out the cause of SrSCD dan how to prevent it. This Study finds that SrSCD occurs mostly in athletes aged $>35$ and the majority cause is due to coronary arterial disease (CAD), while in athletes aged $<35$ the majority cause is due to sudden arrhythmic death syndrome (SADS). SCD can be prevented by doing preparticipation screening, using the "start low, go slow" approach in exercise, following an exercise program that fits to the individual health condition, and management of risk factors.
\end{abstract}

Keywords: Exercise; Sudden cardiac death (SCD); Sports-related sudden cardiac death (SrSCD); Athlete

\section{Introduction}

Sudden death (SD) is defined as natural death that occurs within 6 hours of initial occurrence of symptoms on a previously healthy subject or in subjects that suffers from mild non-life-threatening diseases. Sudden cardiac death (SCD) therefore is defined as a result of cardiovascular malfunction. Sports-related Sudden Cardiac Death is defined as death that occurs during of 1 hour after exercise. Competitive sport is defined as an organized event that are certified by an association or official sporting authorities. All other SD regarding exercise is categorized as non-competitive or recreational [1].

SD currently is heavily associated with sports ad exercise. Even though SD following physical activities has a relatively low incidence rate, these deaths still have a significant impact of those close to the athletes that suffers from SD [1]. Exercise when practiced with intensity and density much greater than the body is capable of has proven to increase the risk of sudden death during or after exercise [2].

Exercise can give a positive impact on the body and a negative impact if done incorrectly. This article will discuss the probable cause of SrSCD and ways to prevent its occurrence.

\section{Epidemiology in Athletes}

The Occurrence of SCD across North America and Europe, as a whole numbered around 500 to 1000 per year in the general population. SrSCD can occur to anyone [1]. In Germany for example, overall incidence of SrSCD on athletes aged 18 is numbered 1, 2 per million per year. While teenagers aged $<18$ the incidence rate is 0 , 4 per million per year [3].

\footnotetext{
${ }^{*}$ Corresponding author: Muhammad Gazi Yasargil

Faculty of Medicine, Airlannga University, Indonesia.

Copyright (C) 2022 Author(s) retain the copyright of this article. This article is published under the terms of the Creative Commons Attribution Liscense 4.0.
} 
In Asian countries, research regarding SrSCD is very rare and not very thorough, the prevalence of SrSCD in Singapore only is about $86,7 \%$, which is 72 out of 83 patients [4,5]. On athletes themselves the number of deaths is relatively small, only 100 to 150 deaths in competitive sports in the United States every year, though at a significant emotional impact on the family of the athletes [6].

\section{Etiology of SrSCD in Atheletes}

Etiology of SrSCD form several studies divide the ages of the participant to with 35 being the cut off age. In ages $<35$, SrSCD occurs mostly due to myocarditis followed by premature CAD [3].

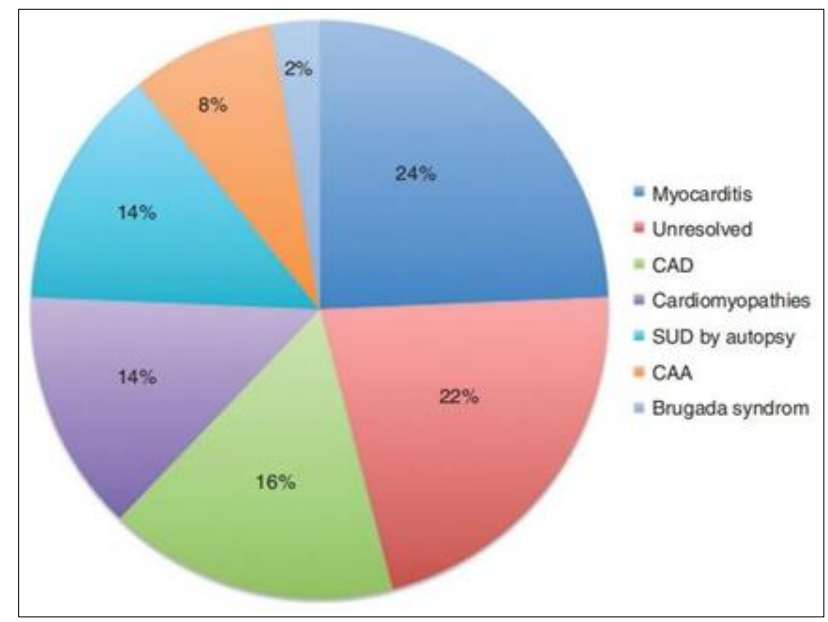

Figure 1 Cause of SrSCD in athletes aged <35 (Bohm, Scharhag and Meyer, 2016)

In the United States, Athletes aged below 35 SrSCD occurs due to inherited cardiovascular disease, hypertrophic cardiomyopathy, and coronary arterial anomaly [7]. A study by Finocchiaro et al [8] (2016) shows that out of 357 athletes, cause of SCD can be based on age, with athletes aged 18 - 35 sudden arrhythmic death syndromes being the most common cause.

The occurrence of SCD proportionally affects competitive athletes aged above 35 years old with incidence as much as 21 per million every year [7]. Cause of SCD in athletes aged $>35$ is most common due to coronary arterial dieseas (CAD) the incidence of SCD due to CAD numbered 13.7 per 100,00 [9]. Even though exercise can decrease the risk of CAD and other cardiovascular diseases, if patients are predisposed to CAD and performing a high intensity exercise it can increase the risk of SCD [7].

\subsection{Athletes > 35 years old: Mechanism of CAD (Coronary Arterial Disease)}

Mechanism of SrSCD due to CAD is not fully understood, however there are several hypotheses regarding mechanism of SCD including the activation of the sympathetic nerve system, electrolyte, and metabolic factors, and also the activation of hemodynamic system in the body [10]. The existence of coronary plaque, fibrosis, and thrombosis is an important characteristic in SCD incidence, especially if the patient is exposed to risk factors such as smoking, high blood pressure, and diabetes [11].

Pathophysiology of SrSCD due to CAD can be seen from 3 perspectives, which are pathophysiological perspective, myocardial pathophysiology, and systemic modulation [12]. Vascular pathophysiology of CAD is tied to the characteristic of the plaque in the artery and the changes of the plaque due to plaque rupture and inflammation that lead to arteries being vulnerable to physiological changes due to exercise [12]. Rupture of the coronary plaque that caused SCD due to exercise have the characteristics of thin fibrous cap and multiple vasa vasorum when compared to plaque ruptures that happens during rest, this rupture will then cause aggregation of thrombocytes, causing thrombosis that can lead to sudden cardiac arrest (SCA) [10].

Contribution of myocardium pathophysiology works in tandem with vascular pathophysiology. The creation of scar tissue in the myocardium due to transient ischemic events that can cause opportunistic arrhythmia that is lifethreatening when patient is exposed to stress, such as during exercises. [12]. 


\subsection{Athlete Aged < 35 Years old: SADS and Brugada Syndrome}

Sudden Arrhythmic Death Syndrome (SADS) can be defined as sudden death with negative toxicological analysis [13]. The post-mortem of the hearts morphological structure is still normal, be it macroscopically of histologically [14]. With the assumption of the absence of morphological damage it is the concluded that death is caused by arrythmia [15]. SADS can be caused by channelopathies disease due to electricity such as Long QT Syndrome (LQTS), Brugada Syndrome (BrS), and Catecholaminergic Polymorphic Ventricular Tachycardia (CPVT) [13,16].

One of the possible causes of SADS is Brugada Syndrome. Brugada syndrome is a genetic arrhythmic cardiac disease that that has 3 typical electrocardiographic patterns that are distinct from one another [17]. Brugada syndrome when observed in electrocardiogram is marked by a persistent elevation of the ST segment in the right precordial segment. This syndrome is tied to a high risk of sudden cardiac death that is more dominant on younger males with normal cardiac structure [18].

Type 1 Brugada syndrome in electrocardiogram has the characteristic of a persistant $\geq 2 \mathrm{~mm}$ elevation of the ST segment followed by negative $\mathrm{T}$ wave in the right precordial area (V1-V3). ECG pattern of type 2 Brugada syndrome is marked by TS segment elevation followed by positive $T$ wave that creates a saddle back configuration, while type 3 ECG pattern is marked by $\leq 1 \mathrm{~mm}$ elevation of the ST segment in the right precordial area [18].

Brugada syndrome is tied to the mutation of the SCN5A gene that code the alpha subunit of the natrium channel. Several channelopathies diseases that is life-threatening includes Ventricle tachycardia or Ventricle fibrillation (VT/VF) [19]. Brugada syndrome is usually not directly tied to SrSCD, however the increase of vagal tonus due to chronic athletic preconditioning when and can cause ventricle arrythmia that leads to SCD [20]. Asymptomatic patients of Brugada syndrome is not prohibited to exercise. Symptomatic patients however, are prohibited to exercise if syncope is present and implementation of ICD must be considered. All patients must consume medications for Brugada syndrome to avoid dehydration, excessive sweating, hyperthermia, and avoid exercise when exercising to prevent arrhythmia that could lead to SCD [19].

\section{Prevention}

The fact that exercise can lead to an increased risk of SCD means that it is important that screening before exercising is very important, especially in athletes that are more vulnerable to SCD. Screening Before exercise is usually called preparticipation screening in order to identify the conditions of the predisposed athletes in order to know the risk of injury or certain disease that can be potentially life-threatening. Preparticipation screening includes several components, such as medical record and family records (chest pain, malaise, syncope, cardiovascular disease, steroid use, etc), physical examination (general health, cardiovascular examination, neurological examination, orthopaedic examination), nutritional status, risk factor of heat and hydration, mental health examination [21].

In reality, preparticipation screening has its pros and cons for multiple parties. A study in Italy shows that there is a significant decrease of SCD occurrence (almost 90\%) after the application of preparticipation screening policy when compared to before the application of the policy. This is due to screening can increase the identification of cardiac abnormality (usually cardiomyopathy) so the athletes are disqualified to avoid SCD. However, another study by Van Brabandt et al [22] shows that preparticipation screening is ineffective in several ways such as low detection rate, and the risk of false positive that can cause an athlete that are physically healthy be disqualified.

In Indonesia itself, there are still no specific organization or policy in regard to sports medicine, especially in preparticipation screening in order to reach an optimal health in patients that wants to be physically active, especially athletes. However, there are other ways to prevent SrSCD which is the "start low, go slow" approach, every exercise program must also be specific and fine-tuned to each individual patients, and management of risk factor by consultation and routine check-ups. [23].

\section{Conclusion}

Exercise can cause a negative effect in the form of SCD. Etiology of SrSCD differed based on the age of the patients. In patients aged $>35$ SrSCD is commonly caused by CAD while patients aged $<35$ is commonly caused by SADS. SrSCD can be prevented by preparticipation screening, "start low, and go slow" approach to exercise, tuning of exercise program to fit the individual patients, and management of risk factors. 


\section{Compliance with ethical standards}

\section{Acknowledgments}

I would like to thank the Faculty of Medicine of the University of Airlangga and all the teaching staff of the elective course "Sports Medicine" for their support in the making of this review article. Without their guidance and supervision, the making of this article would have been impossible.

\section{Disclosure of conflict of interest}

The author of this article has no conflict of interest.

\section{References}

[1] Morentin B, Suárez-Mier MP, Monzó A, Molina P, Lucena JS. Sports-related sudden cardiac death due to myocardial diseases on a population from 1-35 years: a multicentre forensic study in Spain. Forensic sciences research. 2019; 4(3): 257-266.

[2] Marijon E, Uy-Evanado A, Reiner K, Teodorescu C, Narayanan K, Jouven X, Gunsen K, Jui J, Chugh SS. 'Sudden Cardiac Arrest During Sports Activity in Middle Age'. Circulation. 2015; 1384-1391.

[3] Bohm P, Scharhag J, Meyer T.'Data from a nationwide registry on sports-related sudden cardiac deaths in Germany', European Journal of Preventive Cardiology. 2016; 23(6): 649-656.

[4] Wang L, Yeo T], Tan B, Destrube B, Tong KL, Tan SY, Chan G, Huang Z, Tan F, Wang YC, Lee J-Y, Fung E, Mak GYK, So R, Wanlapakorn C, Ambari AM, Cuenza L, Koh CH, Tan JWC. Asian Pacific Society of Cardiology Consensus Recommendations for Pre-participation Screening in Young Competitive Athletes. European Cardiology Review. $2021 ; 16$.

[5] Oh YZ. et al.'Sports-Related Sudden Cardiac Deaths in Singapore - An Eleven- Year Review', Annals of the Academy of Medicine, Singapore. 2019; 48(5): 156-160.

[6] Link MS, Estes NAM. 'Sudden cardiac death in the athlete: Bridging the gaps between evidence, policy, and practice', Circulation. 2012; 125(20): 2511-2516.

[7] Wasfy MM, Hutter AM, Weiner RB. 'Sudden Carciac Death in Athlete', MDCVJ |. 2016; 2: 76-80.

[8] Finnochiaro G, Papadakis M, Robertus J-L, Dhutia H, Steriotis AK, Tome M, Mellor G, Merghani A, Malhotra A, Behr E, Sharma S, Sheppard MN. "Etiology of Sudden Death in Sports: Insights From a United Kingdom Regional Registry," JACC journal. 2016; 67(18): hal. 2108-2115

[9] Katritsis DG, Gersh BJ, Camm AJ 'A Clinical Perspective of Sudden Cardiac Death'. Arrhythmia \& Electrophysiology Review. 2016; 5(3): 177-182.

[10] Chugh SS, Weiss JB. 'Sudden Cardiac Death in Older Athletes'. Journal of American College of Cardiology. 2015; 65(5): 493-502.

[11] Sheppard MN. 'Aetiology of sudden cardiac death in sport: a histopathologist's perspective'. British Journal of Sports Medicine, 2012; 46: 15-21.

[12] Myerburg RJ, Junttila MJ. 'Sudden Cardiac Death Caused by Coronary Heart Disease'. Circulation. 2012; 125: 10431052.

[13] Lahrouchi N, Raju H, Lodder EM, Papatheodorou E, Ware JS, Papadakis M, Tadros R, Cole D, Skinner JR, Crawford J, Love DR, Pua CJ, Soh BY, Bhalshankar JD, Govind R, Tfelt-Hansen J, Winkel BG, van der Werf C, Wijeyeratne YD, Mellor G, Till J, Cohen MC, Tome-Esteban M, Sharma S, Wilde AAM, Cook SA, Bezzina CR, Sheppard MN, Behr ER. "Utility of Post-Mortem Genetic Testing in Cases of Sudden Arrhythmic Death Syndrome," Journal of the American College of Cardiology. 2017; 69(17): hal. 2134-2145.

[14] Basso C, Aguilera B, Banner J, Cohle S, d'Amati G, de Gouveia RH, di Gioia C, Fabre A, Gallagher PJ, Leone O, Lucena J, Mitrofanova L, Molina P, Parsons S, Rizzo S, Sheppard MN, Mier MPS, Kim Suvarna S, Thiene G, van der Wal A, Vink A, Michaud K. "Guidelines for autopsy investigation of sudden cardiac death: 2017 update from the Association for European Cardiovascular Pathology," Virchows Archiv. Virchows Archiv. 2017; 471(6): 691-705.

[15] Yuan D, dan Raju H. "Spotlight on sudden arrhythmic death syndrome," Research Reports in Clinical Cardiology. 2019; 10: hal. 57-66. 
[16] Hayasi M, Shimizu W, Albert CM. "The Spectrum of Epidemology Underlying Sudden Cardiac Death," Circ Res. 2015; 116(12): hal. 1887-1906.

[17] Fazio G, Schiro P. Brugada syndrome and sports activity: from history to risk stratification [internet], e-Journal of Cardiology Practice; 2021 [cited 29 December 2021]. Available from: scardio.org/Journals/E-Journal-ofCardiology-Practice/Volume-19/brugada-syndrome-and-sports-activity-from-history-to-risk-stratification.

[18] Brugada R, Campuzano O, Sarquella-Brugada G, Brugada J, Brugada P. “Brugada syndrome," Methodist DeBakey cardiovascular journal. 2014; 10(1): hal. 25-28.

[19] Panhuyzen-Goedkoop NM, Wilde AAM. "Athletes with channelopathy may be eligible to play," Netherlands Heart Journal. 2018; 26(3): hal. 146-153.

[20] Chandra N, Bastiaenen R, Papadakis M, Sharma S. "Sudden cardiac death in young athletes: Practical challenges and diagnostic dilemmas," Journal of the American College of Cardiology. 2013; 61(10): hal. 1027-1040.

[21] Davis DD, Kane SM. Sports Physicals. StatPearls [Internet]. 2020

[22] Van Brabandt H, Desomer A, Gerkens S, Neyt M. Harms and benefits of screening young people to prevent sudden cardiac death. Bmj. 2016; 353.

[23] Paramita BL, Ayuningtyas D. Scoping review: Konsep layanan kedokteran olahraga di rumah sakit. Jurnal Keolahragaan. 2021; 9(1). 